\title{
Role of infective, immunological, and chronic irritative factors in the development of silicosis
}

\author{
G CHIAPPINO AND E C VIGLIANI
}

\author{
From the Clinica del Lavoro "L Devoto," University of Milan, Milan, Italy
}

ABSTRACT The effect of infective, immunological, and irritative factors on the onset and development of silicosis after intratracheal inoculation with $50 \mathrm{mg}$ of tridymite was investigated on 220 specific pathogen free (SPF) female Sprague-Dawley rats. Even after 12 months the rats, always kept in SPF conditions after intratracheal injection of the dust, showed mainly granulomas with little tendency to confluence or to fibrohyalinosis. Chronic infective stimulation was obtained by keeping groups of SPF animals injected with tridymite for three, six, or 12 months in a conventional animal house, where they were exposed to the endemic bacterial flora. In these animals silicosis developed much more rapidly and produced much more severe confluent lesions than in rats always kept in SPF conditions. Horseradish peroxidase and ferritin given by intratracheal injection and by inhalation were histochemically shown mainly in the dust granulomas but did not accelerate the development of silicosis. Exposure to ozone increased the prevalence of lung infections and thus enhanced the silicosis in conventionally kept animals, without modifying the evolution of silicosis in SPF animals. These experiments showed that the presence of bacterial flora, and particularly bronchopulmonary infections, accelerated the development of silicosis and led to the suggestion that individuals subject to frequent bronchopulmonary infections are unfit for occupations necessitating exposure to silica dust.

Since the beginning of the century clinical and experimental observations have shown that infectious diseases of the lung enhance the onset and development of silicosis. For decades tuberculosis was believed to be the sole infection profoundly affecting the course of silicosis, but there has been increasing evidence that other infections can also play an important part. Cases of silicosis latent for years have appeared and rapidly evolved after bronchopulmonary infections. Norvitt ${ }^{1}$ and Palkin ${ }^{2}$ found many more cases of severe silicosis in miners with past pulmonary infections than in miners with no history of respiratory disease. On the other hand, many cases of silicosis in which evolution is arrested and calcification of the nodules occurs are distinguished by the absence of infective factors in the anamnesis. ${ }^{3}$ Experimental inoculation with infecting agents together with the dust led to the development of severe silicosis. ${ }^{4-7}$ Finally, Heppleston ${ }^{8}$ found that in specific pathogen free (SPF) rats, inhalation of quartz did not lead to sclerohyaline nodular

Supported by grant No 6240-00/4/009 from the European Coal and Steel Community.

Received 18 August 1981

Accepted 13 November 1981 silicosis but mostly to endoalveolar alterations, with scanty sclerotic phenomena and a tendency to removal of endoalveolar material via the bronchial tree: in other words less severe lesions than typical silicosis. The presence of antigen-antibody precipitates in the silicotic lesions ${ }^{9}$ and the severity of coal dust pneumoconiosis in subjects with rheumatoid arthritis $^{10}$ suggest that the immune state of the organism, and especially of the lung, is of considerable importance in the development of pneumoconiosis.

Agents causing chronic irritation of the airways, which are often present in the workplace along with dust, may also influence the evolution of pneumoconiotic lesions, possibly by interfering with lung clearance or through other mechanisms.

Thus from publications and from clinical experience, three basic groups of factors emerge that can influence the course of silicosis-infective factors, immunological factors, and chronic irritative factors. To evaluate the rôle of these factors, the present study was devised using rats born and kept in a SPF environment. The aim of the research was to establish:

(1) whether exposure to common infective agents present in a conventional animal house alters the 253 
lung reactions of SPF rats to silica dust;

(2) whether administration of antigens by inhalation in SPF rats alters the pulmonary reactions to silica and whether these antigens tend to concentrate in the silicotic nodule;

(3) if and in what way an irritating agent, such as prolonged inhalation of ozone, modifies the reactions to silica in SPF rats and in rats kept in a conventional animal house.

\section{Materials and methods}

The experiment was carried out with female Sprague-Dawley rats of an average weight of $100 \mathrm{~g}$, born and kept in a SPF environment, and in which bacteriological tests consistently showed complete absence of pathogens or saprophytes in the airways and a mild saprophytic flora only in the terminal portion of the gut. Altogether, 220 rats were used in the three sections of the experiment.

\section{ROLE OF INFECTIVE FACTORS}

Eighty SPF animals were treated with intratracheal suspension of tridymite etched with hydrofluoric acid (ratio of particles 1-2 $\mu=50 \%$ ); 40 were then kept in SPF conditions and 40 were transferred to a conventional animal house with consequent exposure to the bacterial flora normally present there (table 1).

After death the following studies were performed on the lung tissue:

(a) Histological, histochemical, and immunohistochemical study:

Routine histological staining, silver impregnation for reticulin, immunofluorescence for localisation of gammaglobulins in the lung tissue with specific antiserum.

(b) Determination of hydroxyproline (HOP) content of the lung by the spectrophotometric method of Bergman and Loxley."

(c) Bacteriological analysis of the microbial flora of the lung:

qualitative and quantitative examination with culture on various media (Agar-blood in aerobiosis and anaerobiosis, Agar-malt, thioglycollate, malt broth).

(d) Determination of silica content of the lung by means of the ammonium molybdate colorimetric method. ${ }^{12}$

\section{IMMUNOLOGICAL FACTORS}

Horse ferritin and horseradish peroxidase were used to evaluate the influence of inhaled antigens on the lung response to silica and to define their distribution in the lung tissue. These substances were suitable for the purpose since they are stable over time, are easily detectable with histochemical methods, and possess high antigenic power. Table 2 shows the plan of the experiment. The antigens were administered by aerosol using an M-650 DASCO ultrasonic nebuliser (droplet size: $1 \mu$ ) with an airtight mask adaptable to each animal.

After death, which occurred 24-48 hours after the last inhalation of antigen, the lung was fixed and frozen and then used for:

(a) Histological comparison of lung tissue with SPF rats treated with tridymite alone (see part 1 of the experiment).

(b) Localisation of ferritin in the lung under immunofluorescence on sections treated with anti-horse-ferritin rabbit serum.

(c) Localisation of peroxidase in the lung with the benzidine histochemical method. ${ }^{13}$

\section{ROLE OF CHRONIC IRRITATIVE FACTORS}

Ozone was chosen because it can be readily produced and administered and is safe to handle experimentally, and also because it is often present in working environments.

An atmospheric $\mathrm{O}_{3}$ concentration of $2 \mathrm{mg} / \mathrm{m}^{3}$ (1 ppm) was produced in inhalation chambers with an adjustable ventilation system and equipped with $\mathrm{O}_{3}$ generators giving an $20 \mathrm{mg} / \mathrm{h}$ flow. The rats pretreated with tridymite were exposed for eight hours a day, five days a week until death (table 3 ).

After death the following studies were made on the lung tissue-histological examination, determination of silica, and bacteriological analysis.

\section{Results}

\section{ROLE OF INFECTIVE FACTORS}

Pathology

Pathological examination of the lung tissue showed

Table 1 Treatment carried out on 40 SPF and 40 conventionally kept rats to discover role of infective factors

\begin{tabular}{|c|c|c|c|c|c|}
\hline \multirow[t]{2}{*}{ Animals } & \multirow{2}{*}{$\begin{array}{l}\text { Initial } \\
\text { treatment }\end{array}$} & \multirow[t]{2}{*}{ Maintenance } & \multicolumn{3}{|c|}{ Killed at (months) } \\
\hline & & & 3 & 6 & 12 \\
\hline 80 SPF rats & $\begin{array}{l}50 \mathrm{mg} \text { tridymite in } 0.5 \mathrm{cc} \\
\text { physiological saline, intratracheally }\end{array}$ & $\begin{array}{l}40 \text { SPF } \\
40 \text { kept conventionally }\end{array}$ & $\begin{array}{l}15 \\
15\end{array}$ & $\begin{array}{l}15 \\
15\end{array}$ & $\begin{array}{l}10 \\
10\end{array}$ \\
\hline
\end{tabular}


Table 2 Treatment carried out on 40 SPF rats to discover role of immunological factors

\begin{tabular}{lllll}
\hline Animals & Initial treatment & Subsequent treatment & Killed at (months) \\
\cline { 2 - 4 } & & & 3 & 6 \\
\hline 40 SPF rats & $\begin{array}{l}20 \text { rats: } 50 \mathrm{mg} \text { tridymite }+0.25 \mathrm{mg} \\
\text { ferritin in } 0.5 \mathrm{ml} \text { physiological saline, } \\
\text { intratracheally }\end{array}$ & $\begin{array}{l}0.25 \mathrm{mg} \text { ferritin by aerosol every } \\
15 \text { days in SPF condition }\end{array}$ & 10 & 10 \\
& $\begin{array}{l}20 \text { rats: } 50 \mathrm{mg} \text { tridymite }+0.25 \mathrm{mg} \\
\text { peroxidase in } 0.5 \mathrm{ml} \text { physiological } \\
\text { saline, intratracheally }\end{array}$ & $\begin{array}{l}0.25 \mathrm{mg} \text { peroxidase by aerosol every } \\
15 \text { days in SPF condition }\end{array}$ & 10 & 10 \\
\hline
\end{tabular}

Table 3 Treatment carried out on 100 SPF rats to discover role of chronic irritative factors

\begin{tabular}{|c|c|c|c|c|}
\hline Animals & Initial treatment & Subsequent treatment & $\underset{6}{K i l}$ & ths) \\
\hline \multirow[t]{2}{*}{100 SPF rats } & \multirow[t]{2}{*}{$\begin{array}{l}50 \mathrm{mg} \text { tridymite in } 0.5 \mathrm{ml} \text { physiological } \\
\text { saline, intratracheally }\end{array}$} & $\begin{array}{l}\text { SPF: } \\
\text { Ozone } 2 \mathrm{mg} / \mathrm{m}^{3} 8 \mathrm{~h} / \text { day }\end{array}$ & 25 & 25 \\
\hline & & $\begin{array}{l}\text { Conventionally kept: } \\
\text { Ozone } 2 \mathrm{mg} / \mathrm{m}^{3} 8 \mathrm{~h} / \text { day }\end{array}$ & 18 & 10 \\
\hline
\end{tabular}

that the alterations produced by tridymite in the animals always kept in SPF conditions differed from the alterations observed in the rats exposed, after treatment, to the common saprophytic and pathogenic bacteria of a conventional animal house. Three months after treatment, the lungs of the animals kept SPF contained small interstitial macrophagic, non-confluent granulomas with very little tendency to fibrohyalinosis; dust particles were found in the alveoli in extensive areas of the lungs together with foam cells and amorphoacidiphilic material similar to that seen in alveolar proteinosis. At six and 12 months the pattern had changed slightly with some increase in volume of the granulomas, which exhibited moderate central fibrosis and scanty hyaline transformation, but always without confluence; the picture continued to show dispersion of the dust in the alveolar spaces and a non-specific alveolar reaction (figs 1, 2).

In the conventionally kept rats, however, the picture at three months was dominated by the presence of nodules with central sclerohyalinosis and by the concentration in these nodules of nearly all the dust particles present in the lung tissue; after six, and particularly after 12 months, a silicosis developed with large nodules and confluent masses (figs 3, 4).

Under immunoffuorescence with rat antigammaglobulin labelled serum, plasma cells and gammaglobulin deposits could be found around the nodules only in rats kept conventionally and killed at six and 12 months.

\section{Biochemical data}

Figure 5 gives the hydroxyproline content of the lung tissue, in $\mu \mathrm{g} / \mathrm{mg}$ dry weight, which is the quantifiable expression of the extent of collagenisation.

Compared with the base values of SPF untreated control rats and with the value in rats treated with tridymite and kept SPF, the values in the conventionally kept rats were already much higher at three months, and the differences became even more evident at six months. The mean hydroxyproline values were compared using the paired $t$ statistic, one tailed. At three months the mean hydroxyproline value in control rats did not differ significantly from that in SPF rats $(t=1.655 \mathrm{p}>0.05)$, while the difference between control and conventionally kept rats were significant $(t=5.59 \mathrm{p}<0.001)$. Again, after six months the mean hydroxyproline value in untreated rats differed significantly only from the mean values in conventional rats $(t=9.7 \mathrm{p}<$ $0 \cdot 001$ ). No measurement was made in the rats killed at 12 months because of the presence of severe infective alterations, with areas of confluent necrotising microabscesses in the lungs of many conventionally kept animals.

\section{Bacteriological data}

Qualitative and quantitative examination showed complete absence of saprophytes and pathogens in the lungs of SPF-maintained rats. The microbial flora of the lungs of the conventionally kept rats consisted of staphylococci (2500-4000/g tissue) and streptomyces $(300-800 / g$ tissue). Conventionally kept rats killed after one year showed the highest degree of bacterial contamination.

Silica content of the lung tissue

The values varied widely from one animal to 


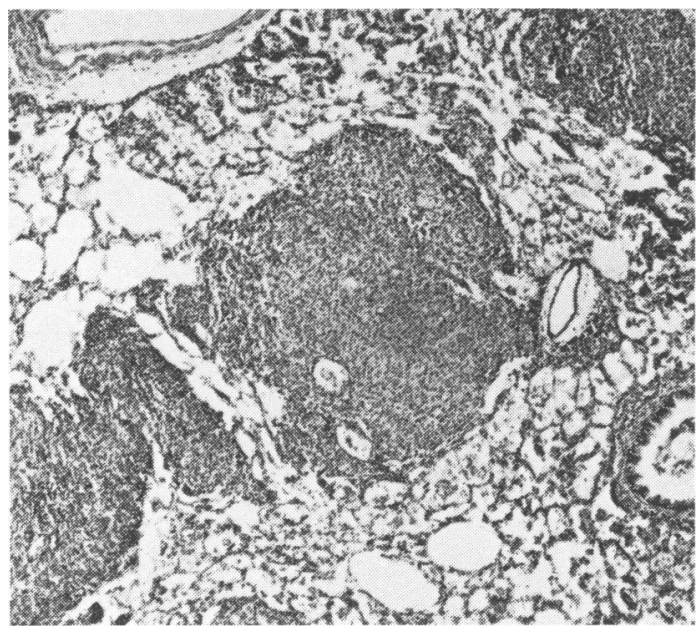

Fig 1 Lung of SPF rat killed 12 months after intratracheal inoculation with tridymite: microgranulomas with scarce tendency to confuence, without hyalinosis $(E E \times 100)$.

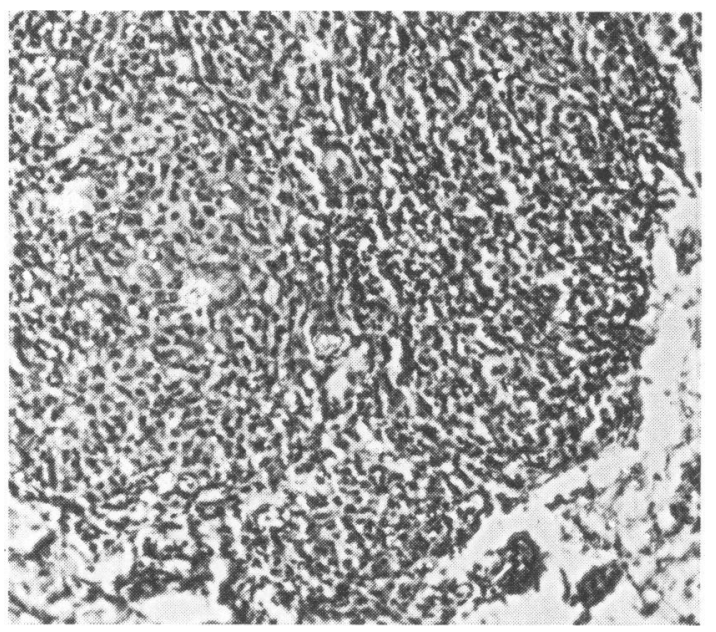

Fig 2 Greater enlargement of fig 1. Scarce tendency to sclerohyalinosis is more clearly visible. Numerous birefringent tridymite particles are scattered in granuloma, some still appearing in alveolar spaces (EE phase contrast $\times$ 500).

another, probably because the determination was not made on the whole lung but on the residual part of the tissue after the necessary samples had been taken for other examinations, and because of the irregular distribution of the dust injected in the trachea. The mean values observed for different

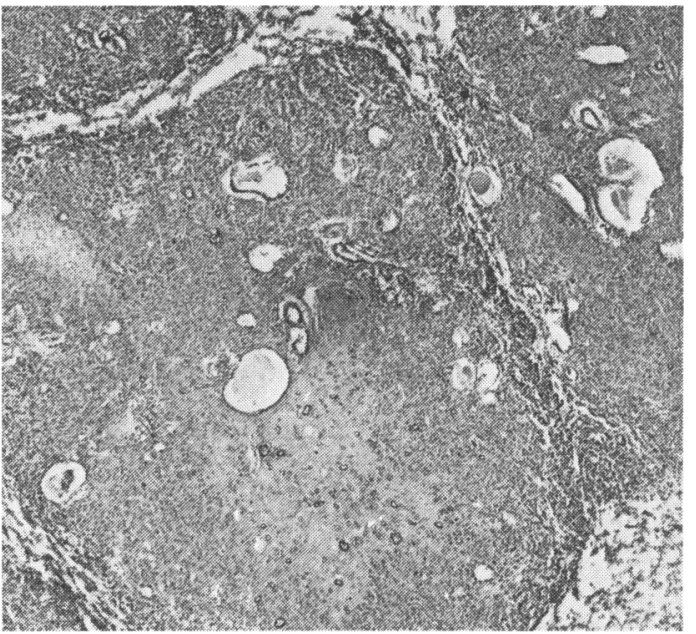

Fig 3 Lung of conventionally kept rat killed 12 months after intratracheal inoculation with tridymite. Confluent granulomas with manifest central hyalinosis $(E E \times 100)$.

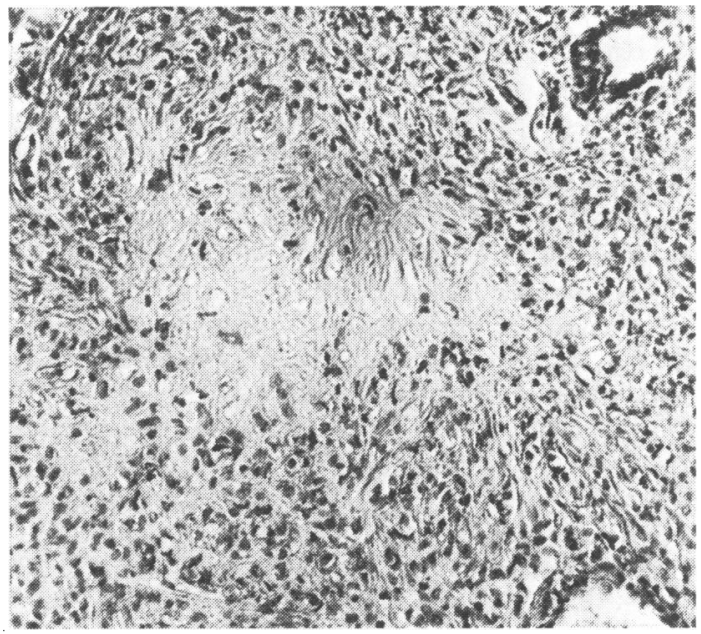

Fig 4 Lung of conventionally kept rat killed 12 months after intratracheal inoculation with tridymite.

Sclerohyalinosis evident in central zone (EE phase contrast $\times 500)$.

groups, however, indicate that the varying severity of the silicotic lesions is not related to the total dust retention of the lung. Table 4 gives the mean values observed in the rats killed at six months. Statistical analysis showed no significant difference between the mean values observed for the two groups. 


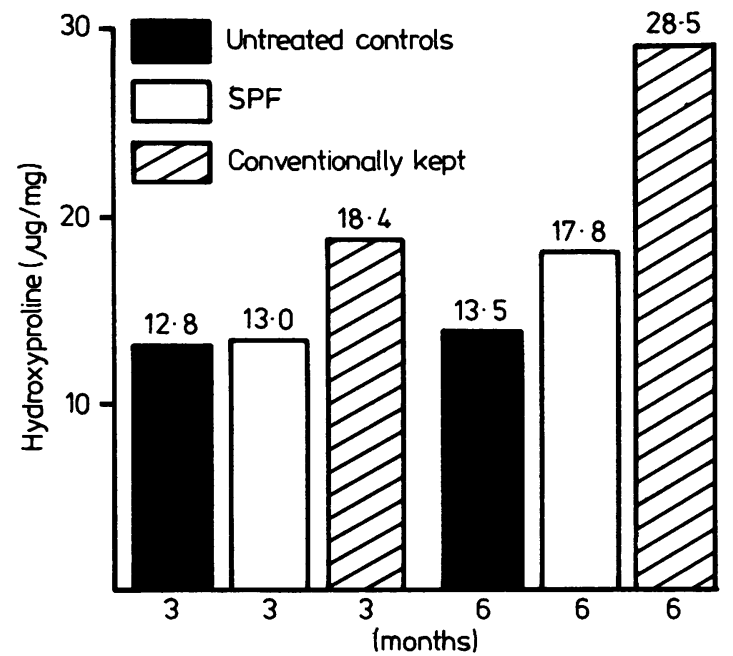

Fig 5 Hydroxyproline content of lungs of rats in $\mu \mathrm{g} / \mathrm{mg}$ dry weight.

Table 4 Mean values observed in rats killed at six months

\begin{tabular}{lll}
\hline & SPF & Conventionally kept \\
\hline $\begin{array}{l}\text { Silica (mg/g dry } \\
\text { lung tissue) }\end{array}$ & $9 \cdot 4 \pm 3.2$ & $8.5 \pm 2 \cdot 7$ \\
\hline
\end{tabular}

Role of immunological factors

The pulmonary picture of the SPF rats treated with both tridymite and ferritin or peroxidase did not show qualitative or quantitative differences from the rats treated with tridymite alone. Specific histochemical staining for ferritin and peroxidase, however, showed a pronounced tendency for these antigens to concentrate in the dust deposits and in the interstitial macrophagic granulomas, and sometimes in the cytoplasm of the macrophages containing silica particles. Immunohistochemical staining with rat antigammaglobulin fluorescent serum showed no plasma cells, nor localisations that could be interpreted as antibody precipitates at sites where antigens were present, nor anywhere else in the lungs.

\section{Role of chronic irritative factors}

Prolonged exposure to $\mathrm{O}_{3}$ in our experimental conditions was well tolerated by the rats treated with tridymite and kept SPF. In the conventionally kept rats about half died, all from purulent bronchopneumonia.

The lungs of the SPF-maintained rats showd consistent alterations clearly distinguishable at six months and more evident at 12 months-that is, hyperplasia of the bronchial and bronchiolar epithelia, with swelling of the alveolar cells, mild interstitial oedema, and very slight fibrosis. These alterations were often in lung areas far away from the macrophagic dust granulomas, which were identical in distribution, appearance, and extent to those observed in SPF rats treated only with tridymite. The conventionally kept rats that died spontaneously during the experiment or that were killed at six and 12 months showed hyperplasia of the bronchiolar and alveolar epithelia, as did the SPF rats, but in conventionally kept rats it was associated with, and at certain sites masked by, the co-existence of bronchitis and purulent bronchiolitis, and foci of pneumonia often accompanied by microabscesses and necrosis. The dust lesions in these animals were true silicotic nodules exhibiting an ample sclerohyaline core and a tendency to coalesce into large compact masses. Very often the silicotic masses were partially incorporated and necrotised in the abscesses, so that measurement of pulmonary hydroxyproline was not possible. This appearance, compared with that of conventionally kept rats treated with tridymite only was distinguished by the presence.of much more prominent infective lesions.

Determination of the free silica content at six months gave mean values indicating that ozone did not influence the retention of silica and showing no significant differences between SPF and conventionally kept rats: $9 \pm 2.5 \mathrm{mg} / \mathrm{g}$ and $9 \pm 3.4 \mathrm{mg} / \mathrm{g}$ of dry tissue respectively.

Bacteriological analysis confirmed that after six and 12 months' exposure to ozone the lungs of the SPF rats contained no saprophytic or pathogenic organisms; in the conventionally kept rats, however, the lung tissue contained an abundant microbial flora consisting mainly of staphylococci and streptococci.

\section{Discussion}

In agreement with Heppleston, ${ }^{8}$ we confirm that the pathogen-free rats treated with silica developed very slowly evolving pneumoconiosis exhibiting very little fibrosis. But exposure to the saprophytic and pathogenic flora of the routine animal house produced a rapid response to silica in the previously SPF rat, leading to severe and rapidly evolving silicosis.

The differences in rapidity of evolution and in severity of experimental silicosis between SPF and conventionally kept rats did not depend on variations of the amount of dust retained but rather on changes in the reactivity of the animals to the dust, leading to alterations in its distribution-more scattered throughout the whole lung in the SPF rats and more collected in the macrophagic nodules in the conventionally kept animals. 
The association of an antigen with the silica did not alter the lung reaction in the SPF rat, although the antigen was often found to be concentrated in the dust granulomas.

Exposure to ozone produced alterations of the bronchial and alveolar epithelia in the SPF rats, without modifying the reaction to silica; in the conventionally kept rats the same epithelial reactions were elicited but were accompanied by a high prevalence of bronchopulmonary infections and a severe, confluent silicotic sclerohyalinosis.

The demonstration that inhaled ferritin or horseradish peroxidase tended to concentrate in the dustinduced granulomas and particularly in the macrophages leads to the suggestion that respiratory infections might aggravate the evolution of silicosis also through the localisation of antigens, with formation of immunocomplexes exactly at the sites of dust accumulation. Our experiments imply that an antigenic stimulus like ferritin or peroxidase is not sufficient to alter the development of silicosis in SPF rats, even though the antigen is concentrated in the lesions. Thus apparently the continual and multifarious stimuli accompanying daily contact with saprophytic and pathogenic flora can account for the more pronounced response of the lung tissue of conventionally kept rats to injected silica.

Exposure to ozone does not appear to have any effect on dust retention nor, by itself, to modify the lung's reaction to silica; exposure to ozone does, however, exert a significant aggravating effect by potentiating infection. Our observations therefore are not in contrast with those of Ehrlich, ${ }^{14}$ who treated mice with ozone and an infecting aerosol, and showed that ozone increases the susceptibility to respiratory infection. Epidemiological investigations, too, have shown that exposure to atmospheric pollutants sometimes increases the incidence of respiratory infections-for instance, the common cold. ${ }^{15}$

Our experiments have shown that the development of classical sclerotic silicosis in rats is greatly enhanced by minor degrees of pulmonary infection, which is, itself, exacerbated by exposure to an irritant gas. If these findings also apply to man they imply that workers who have frequent bronchopulmonary infections, or who are exposed to irritant gases, should not work in the presence of silica dust.

We are grateful to the Carlo Erba Research Laboratories, which provided animal houses for the SPF rats and the help of trained technicians.

\section{References}

${ }^{1}$ Norvitt L. Die Bedeutung von Primartuberkulose und anderen Lungeninfektionen für die Entstehung der Silikose. Archiv für Gewerbepathologie und Gewerbehygiene 1964;20:587-603.

${ }^{2}$ Palkin VN. On the development and evolution of silicosis after discontinued exposure to the effects of dust. Gigiena Truda 1966;1:30-4.

${ }^{3}$ Moreschi N, Farina G, Chiappino G. La silicosi polmonare calcificata. Med Lav 1968;59:111-24.

4 Cesa-Bianchi D, Devoto L. Patologia polmonare da inalazioni di polveri. Il Lavoro 1911;4:314-6.

${ }^{5}$ Mavrogordato A. Contribution to the study of miner's phthisis. Publications of the South African Institute for Medical Research 1926; No XIX 3:1-84.

- Attygalle D, Harrison CV, King J, Mohanty GP. Infective pneumoconiosis. The influence of dead tubercle bacilli (BCG) on the dust lesions produced by anthracite, coal-mine dust, and kaolin in the lungs of rats and guinea pigs. $\mathrm{Br} J$ Ind Med 1954;11:245-59.

${ }^{7}$ Gernez-Rieux C, Tacquet A, Collet A, Macquet V, Martin JC, Poucard A. Etude experimentale de l'influence de l'empoussierage du poumon sur son infection par les mycobacteries atipyques. C R Acad Sci 1963;257:3103-9.

${ }^{8}$ Heppleston AG. Atypical reaction to inhaled silica. Nature 1967;213:199.

- Vigliani E, Pernis B. Immunological aspects of silicosis. Adv Tuberc Res 1963;12:230-79.

${ }^{10}$ Caplan A. Certain unusual radiological appearances in the chest of coal-miners suffering from rheumatoid arthritis. Thorax 1953;8:29-37.

"Bergman B, Loxley A. Lung tissue hydrolysates: Studies of the optimum conditions for the spectrophotometric determination of hydroxyproline. Analyst 1969;94:575-84.

${ }^{12}$ Kenyon A, Bewick HA. Photometric determination of silica in alkalies. Anal Chem 1963;25:145-8.

${ }^{13}$ Straus W. Improved staining for peroxidase with benzidine and improved double staining immunoperoxidase procedures. $J$ Histochem Cytochem 1972;20:272-8.

14 Erhlich R. Effect of air pollutants on respiratory infection. Arch Environ Health 1963;6:638-42.

is Thompson DJ, Lebowitz M, Cassell EJ. Air pollution, weather, and the common cold. Am J Public Health 1970;60:731-9. 